Results The analysis indicates that there is no significant difference between measurements obtained in either 2D or 3D datasets between the two imaging acquisition techniques for the same operator $(\mathrm{p}=1.000)$.

Conclusion Overall, there is good intra-observer reliability without significant difference of measurements between standard 3D DSA and 3DA techniques. Further development and use of AI techniques can help decrease radiation exposure while maintaining image quality. The concepts and results presented in this paper are based on research and are not commercially available.

Disclosures J. Peterson: None. D. Dornbos: None. J. DiNitto: 5; C; Siemens Medical Solutions. C. Nickele: 1; C; Microvention, Siemens Medical Solutions. 4; C; Marblehead Medical. D. Hoit: 1; C; Siemens Medical Solutions. 2; C; Siemens Medical Solutions, Medtronic, Microvention, Cerebrotech. 4; C; Silver Bullet Thereupetics. L. Elijovich: 1; C; Siemens Medical Solutions. 2; C; Medtronic, Scientia Vascular, Stryker, VizAI, Microvention, Cerenovus. N. Goyal: 1; C; Siemens Medical Solutions. C. Kaethner: 5; C; Siemens Medical Solutions. R. Setser: 5; C; Siemens Medical Solutions. A. Arthur: 1; C; Siemens Medical Solutions. 2; C; Siemens Medical Solutions, Microvention, Scientia Vascular, Pneumbra, Stryker, Medtronic, Johnson \& Johnson, Codman Neuro, Balt. 4; C; Mentice Simulations. M. Kowarschik: 5; C; Siemens Medical Solutions. V. Inoa-Acosta: 1; C; Siemens Medical Solutions. 2; C; Siemens Medical Solutions, Cerenovus, Orbees, Scientia Vascular.

\section{E-077 PIPELINE EMBOLIZATION OF MCA ANEURYSMS IN THE M2-M4 SEGMENT: MULTICENTER COHORT AND META- ANALYSIS}

${ }^{1} \mathrm{D}$ Lauzier*, ${ }^{1} \mathrm{~B}$ Root, ${ }^{2}{ }^{2}$ Kayan, ${ }^{2} \mathrm{~J}$ Delgado Almandoz, ${ }^{3} \mathrm{~J}$ Osbun, ${ }^{3} \mathrm{~A}$ Chatterjee, ${ }^{2} \mathrm{~K}$ Whaley, ${ }^{2} \mathrm{M}$ Tipps, ${ }^{4} \mathrm{C}$ Moran, ${ }^{3} \mathrm{~A}$ Kansagra. ${ }^{1}$ Mallinckrodt Institute of Radiology, Washington University School of Medicine, St. Louis, MO; ${ }^{2}$ Abbott Northwestern Hospital, Minneapolis, $M N$; ${ }^{3}$ Mallinckrodt Institute of Radiology, Department of Neurological Surgery, Department of Neurology, Washington University School of Medicine, St. Louis, MO; ${ }^{4}$ Mallinckrodt Institute of Radiology, Department of Neurological Surgery, Washington University School of Medicine, St. Louis, MO

\subsection{6/neurintsurg-2021-SNIS.172}

Introduction/Purpose Flow diversion of distal MCA aneurysms in the M2-M4 segments with PED is promising, but further study is needed. Here, we seek to quantify the safety and efficacy of Pipeline embolization in the M2-M4 region in a multi-center cohort and comprehensive metaanalysis.

Materials and Methods Clinical and angiographic data of eligible patients was retrospectively obtained from participating centers and assessed for key clinical and angiographic outcomes. A literature search was conducted with defined search criteria, and studies meeting inclusion criteria were included with our multi-center cohort in a meta-analysis quantifying rates of aneurysm occlusion and clinical complication. Outcomes were pooled across studies with a random effects model and rates of aneurysm occlusion and complication are

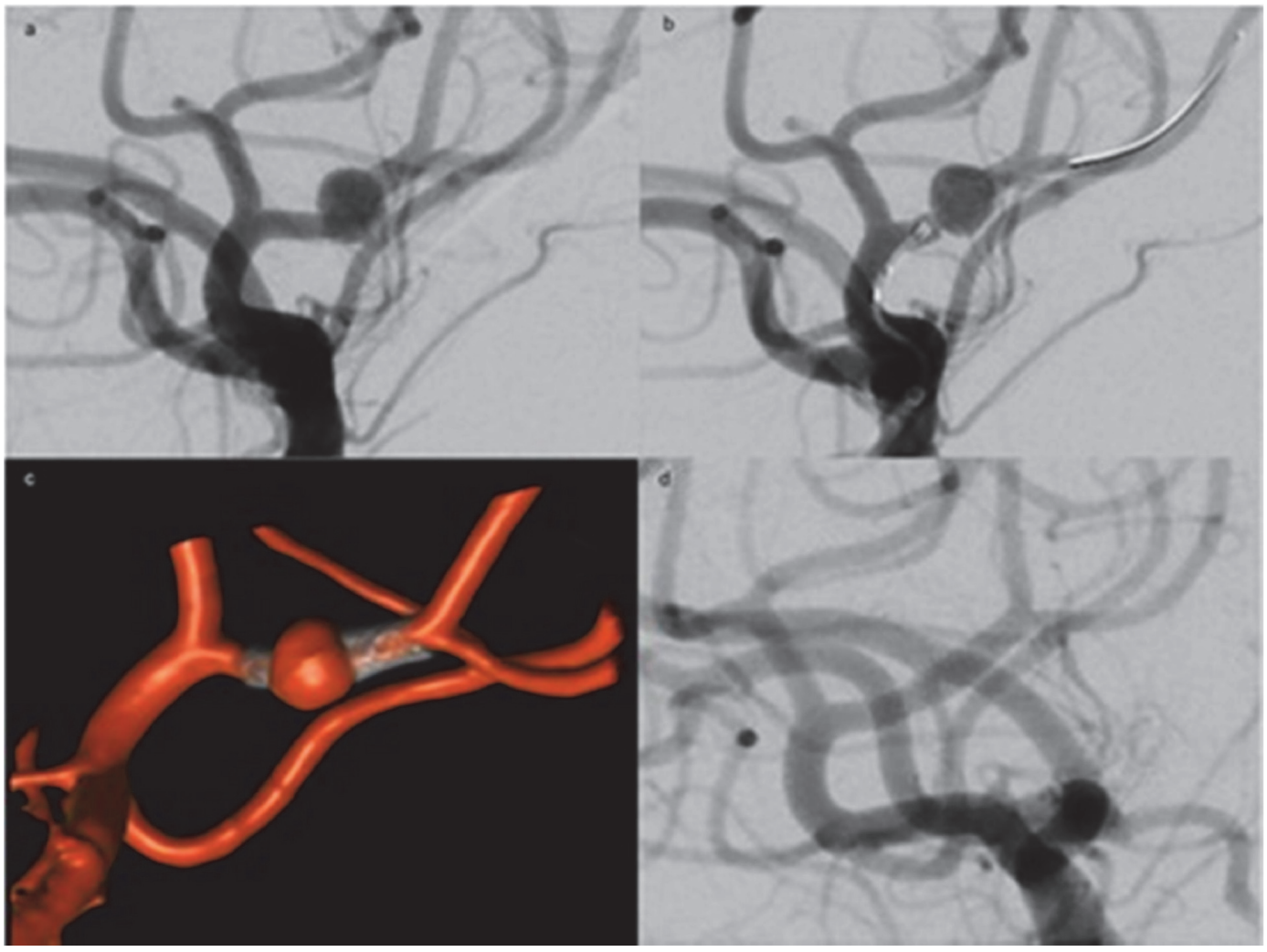

Abstract E-077 Figure 1 Angiographic images of a right M3 aneurysm in Patient 5 showing preoperative angiography (a), angiography during deployment of a $2.5 \times 10 \mathrm{~mm}$ Pipeline Embolization Device (b), post-deployment 3D rotational angiography showing device position (c), and followup angiography at 6 months showing complete aneurysm occlusion (d) 
reported as estimated sample means with a 95\% confidence interval.

Results In our multi-center cohort, aneurysm occlusion was achieved in $88 \%(7 / 8)$ of treated aneurysms and clinical complications occurred in $0 \%(0 / 6)$ of patients. An illustrative example from our cohort is provided in figure 1 . In our meta-analysis of 46 aneurysms from 7 studies, the rate of aneurysm occlusion was $81 \%$ (95\% CI, 69\%-92\%) and the rate of clinical complications was 10\% (95\% CI, 2\%-18\%).

Conclusions Pipeline embolization of cerebral aneurysms of the M2-M4 segments of the MCA was reasonably effective and safe in a small group of selected patients. Further study is needed to validate these results.

Disclosures D. Lauzier: None. B. Root: None. Y. Kayan: 2; C; Microvention, Penumbra, Medtronic. J. Delgado Almandoz: 2; C; Medtronic, Microvention. J. Osbun: 2; C; Medtronic, Microvention. A. Chatterjee: None. K. Whaley: None. M. Tipps: None. C. Moran: 2; C; Medtronic, Cerenovus. A. Kansagra: 2; C; Penumbra, Microvention, iSchemaView.

\section{E-078 PIPELINE EMBOLIZATION OF PROXIMAL MIDDLE CEREBRAL ARTERY ANEURYSMS: A MULTICENTER COHORT STUDY}

${ }^{1} \mathrm{D}$ Lauzier*, ${ }^{1} \mathrm{~B}$ Root, ${ }^{2}{ }^{2}$ Kayan, ${ }^{2} \mathrm{~J}$ Delgado Almandoz, ${ }^{3} \mathrm{~J}$ Osbun, ${ }^{3} \mathrm{~A}$ Chatterjee, ${ }^{2} \mathrm{~K}$ Whaley, ${ }^{2} \mathrm{M}$ Tipps, ${ }^{4} \mathrm{C}$ Moran, ${ }^{3} \mathrm{~A}$ Kansagra. ${ }^{1}$ Mallinckrodt Institute of Radiology, Washington University School of Medicine, St. Louis, MO; ${ }^{2}$ Abbott Northwestern Hospital, Minneapolis, $M N{ }^{3}$ Mallinckrodt Institute of Radiology, Department of Neurological Surgery, Department of Neurology, Washington University School of Medicine, St. Louis, MO; ${ }^{4}$ Mallinckrodt Institute of Radiology, Department of Neurological Surgery, Washington University School of Medicine, St. Louis, MO

\subsection{6/neurintsurg-2021-SNIS.173}

Introduction/Purpose Flow diversion of aneurysms located in the M1 segment and middle cerebral artery bifurcation with Pipeline embolization device is sometimes performed, but further study is needed to support its regular use in aneurysm treatment. Here, we report measures of safety and efficacy for Pipeline embolization in the proximal middle cerebral artery in a multi-center cohort.

Materials and Methods Clinical and angiographic data of eligible patients undergoing Pipeline embolization of aneurysms

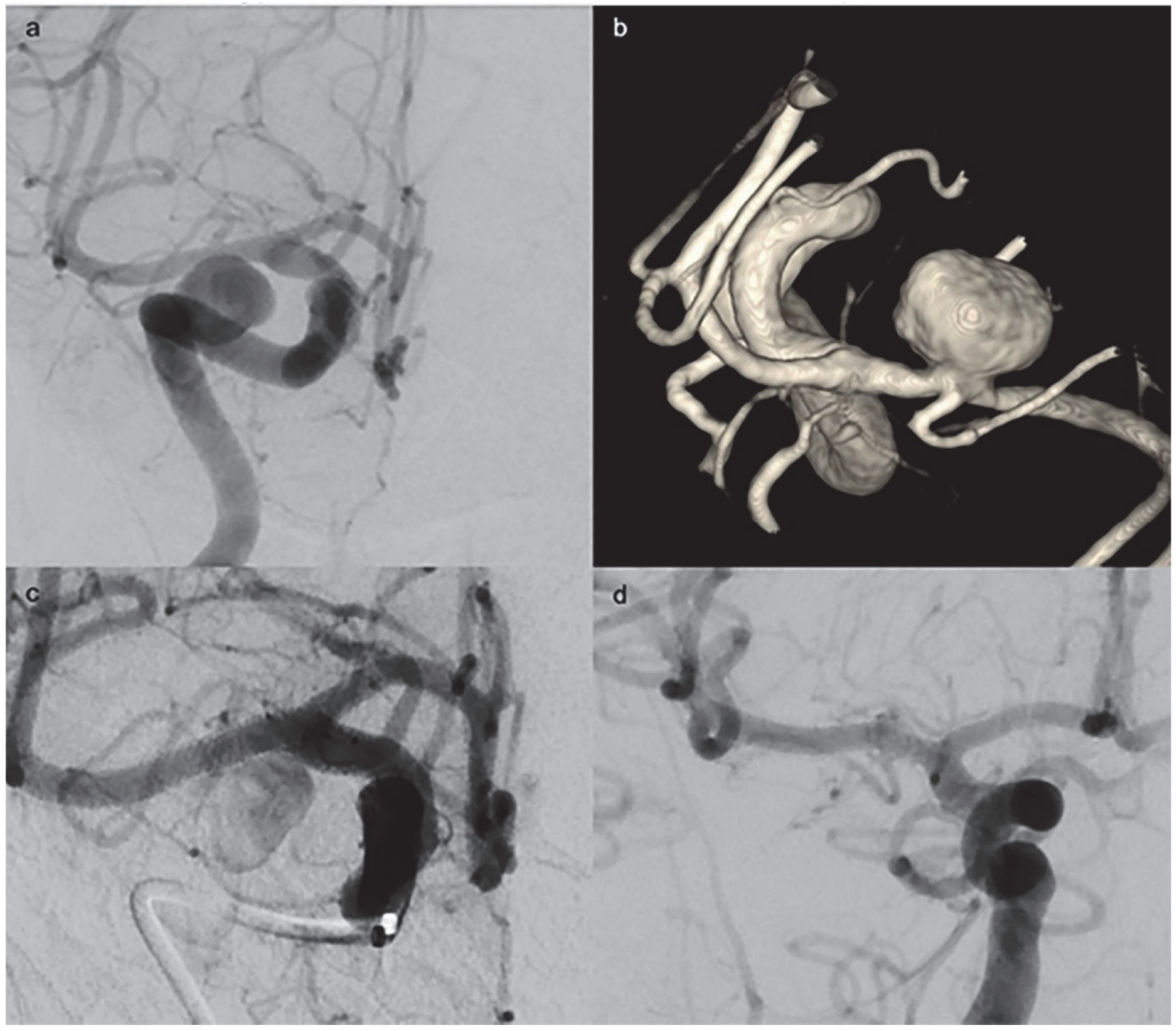

Abstract E-078 Figure 1 (a) Pre-treatment angiography and (b) pre-treatment 3D reconstruction show a $13.4 \times 12.0 \mathrm{~mm}$ aneurysm of the right M1 segment. (c) Immediate post-treatment angiography following deployment of $3.25 \times 14 \mathrm{~mm}$ PED showing contrast stasis within the aneurysm. (d) 32 month follow-up angiography demonstrates complete occlusion of the aneurysm 